Case Study

\title{
External focus training for reacquisition of knee function in a Down syndrome patient after surgery for recurrent patellar dislocation: a case report
}

\author{
Kyoko Kanae, RPT ${ }^{1)}$, Hirotaka Mutsuzaki, MD, PhD²), Yoshihide Kanai, RPT, PhD ${ }^{3)^{*}}$ \\ 1) Department of Physical Therapy, Ibaraki Prefectural University of Health Sciences Hospital, Japan \\ 2) Department of Orthopaedic Surgery, Ibaraki Prefectural University of Health Sciences, Japan \\ 3) Department of Physical Therapy, Ibaraki Prefectural University of Health Sciences: 4669-2 Ami-machi \\ Ami, Inashiki-gun, Ibaraki 300-0394, Japan
}

\begin{abstract}
Purpose] This case study describes the reacquisition of knee joint function in a patient with Down syndrome after surgery for patellar dislocation using external focus training. [Participant and Methods] The patient was a female aged 24 years with Down syndrome and a low Intelligence Quotient, who suffered from right patellar dislocation. The range of motion in the right knee while walking was 2 to 23 degrees at 3 weeks after surgery. A compensatory gait while walking was confirmed, with her right leg fixed in extension. Her range of motion while lying was 0 to 155 degrees. A task in which the patient reached and touched a ball was performed with the lower extremities while lying down, according to simple instructions from a therapist. Instructions were given using a simple directive phrase. The intervention started with a single-joint exercise and progressed to a multi-joint exercise. [Results] The range of motion was 0 to 68 degrees at 9 weeks after surgery. Her compensatory gait disappeared and she was able to walk more than $2 \mathrm{~km}$. [Conclusion] Even though the patient's low cognitive function made it difficult for her to complete some tasks, training based on external focus enabled her to acquire adequate knee joint function. External focus training was found to be effective for a patient with a low Intelligence Quotient. Key words: Down syndrome, Recurrent patellar dislocation, External focus
\end{abstract}

(This article was submitted Jul. 22, 2018, and was accepted Sep. 12, 2018)

\section{INTRODUCTION}

Down syndrome (DS) is a congenital disease caused by an autosomal abnormality (trisomy 21$)^{1,2)}$. People with DS experience developmental delay in both mental and motor function ${ }^{3}$. Hypotonus and joint laxity have often been confirmed in people with $\mathrm{DS}^{4}$. These characteristics involve numerous orthopedic complications ${ }^{5,6)}$, including patellar instability ${ }^{7)}$ and patellar dislocation ${ }^{8}$. In terms of cognitive function, the Intelligence Quotient (IQ) of people with DS is generally lower than that of typically developing children. The level of cognitive impairment is variable and may be mild (IQ of 50-70) to severe (IQ of 20-35) ${ }^{5}$. People with DS often have difficulties in both expressing and understanding language, and visual information is therefore important for learning ${ }^{9}$ ).

The ability to focus attention is important for motor learning. Instructions given while learning motor skills are related either to movements on the subject's own body or to the effects of those movements on the apparatus (e.g., golf club, ball, skateboard, tennis racket), which involve internal focus and external focus, respectively ${ }^{10}$. It means that paying attention to a certain part of his/her body at internal focus and paying it to outside bodies at external focus. External focus can enhance motor learning better than internal focus in both healthy children and in children with low IQ ${ }^{10,11)}$. Therefore, we believed that the concept of the external focus can be helpful for people with DS, and based the training on the idea.

*Corresponding author: Yoshihide Kanai (E-mail: kanai@ipu.ac.jp)

(C2018 The Society of Physical Therapy Science. Published by IPEC Inc.

(c) (i) $(-)$ This is an open-access article distributed under the terms of the Creative Commons Attribution Non-Commercial No DerivaCC BY NC ND tives (by-nc-nd) License. (CC-BY-NC-ND 4.0: https://creativecommons.org/licenses/by-nc-nd/4.0/) 
As far we are aware, there have been no previous reports on the use of external focus training (EFT) in postoperative physical therapy for patellar dislocation in DS. The aim of this case report is to describe the process of the re-acquisition of knee joint function during walking in a DS patient with a low IQ after surgery for patellar dislocation using an intervention based on EFT.

\section{PARTICIPANT AND METHODS}

This case report was approved by the Ibaraki Prefectural University of Health Sciences Ethics Committee (approval no. 777). Then, we provided sufficient explanation to the patient's family who inferred the will of the patient and obtained written consent before the intervention. The patient was a 24 year-old female who commenced walking at the age of 1 year 8 months. We provided sufficient explanation to the patient's family who inferred the will of the patient and obtained written consent before the intervention. She preferred walking or playing with a ball. Her IQ, tested with the Tanaka-Binet Intelligence Scale ${ }^{12)}$, was 20 . Active speech was difficult, but she could follow simple instructions and imitate others' behavior. The patient had flat feet and was diagnosed with recurrent dislocation of the patellar on her right side when she was 10 years old. Her knee joint was supported with a knee brace. After experiencing worsening pain at 23 years old, limited range of motion (ROM) in her knee joint and lameness were confirmed. At the time, the patellar was completely dislocated to the lateral side with the knee joint flexion at 90 degrees. When she was 24 years old, reconstruction of the right medial patellofemoral ligament (MPFL) was performed using a semitendinosus tendon graft in another hospital. Her right knee was fixed in an extended position using a knee brace. She was admitted to a rehabilitation hospital at the seventh postoperative day.

The patient experienced pain at 55 degrees of the ROM of the right knee in flexion, and the limitation of her ROM was confirmed as -5 degrees in extension. This value was considerably lower than that of the other side. Manual muscle tests could not be implemented because of the patient's limited cognitive function. While walking without a knee brace, she could walk only 100 meters at a time, and her right lower extremity was fixed in an extended position through all phases. The patient compensated by swinging the leg in an outward trajectory in the swing phase. Her trunk bent to the right and left while walking. This gait continued even after the knee brace was removed 3 weeks after surgery (Fig. 1). The ROM of the right knee during walking was 2 to 23 degrees 3 weeks after surgery. The walking speed was $0.83 \mathrm{~m} / \mathrm{s}$, and the step length was $24.0 \mathrm{~cm}$. We took videography of the patient's gait on sagittal plane. Then, we calculated the angle using a markerless 2D video-based analysis (Frame-DIAS, DKH Co., Ltd., Tokyo, Japan).

At 4 weeks after surgery, flexion of the knee joint during walking appeared in the swing phase with an improvement in the ROM. However, it became hyperextended in the early stance phase. Selective movements of the knee and hip joint were difficult even under no loading. The motion pattern of the knee remained fixed in an extended position, similar to straight leg raising. This seemed to be the result of both muscle weakness in the lower extremity and a lack of dynamic control ability in the hip or knee joints. Therefore, we aimed to improve the function of her knee joint.

In the early stage of the intervention, a specific type of mobilization and joint mobility practice were implemented, taking into consideration the inflammation of the surgical wound. Next, an active exercise called EFT to control her lower leg, especially right knee joint, were practiced. Since she couldn't move her right knee selectively, the task involved reaching the lower extremities toward a ball and was conducted while lying to ensure there was no loading on the right leg (Fig. 2). During the practice, we used a ball as a target because she preferred to reach toward an object. To perform the task, she lay in a supine position, and the therapist placed a ball at a specific place to encourage her to reach and touch it with her toe and/or her knee. We gave her a simple instruction to "touch the ball". The practice started with a single-joint exercise, and gradually progressed to a multi-joint exercise which moves hip joint and knee joint at the same time. A single-joint exercise is a practice

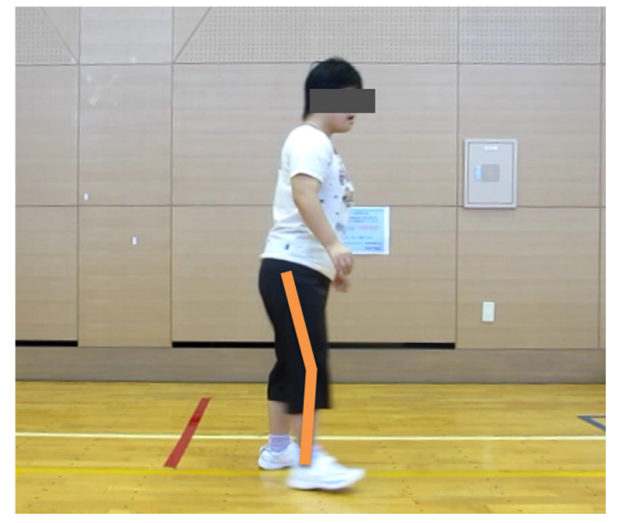

Fig. 1. Right knee joint while walking (Midswing phase).

3 weeks after surgery; knee joint fixed to the extended position. 
to selectively move just one joint such as, ankle, knee, hip and so on. A multi-joint exercise is that to simultaneously move plural joints such as ankle and knee, or knee and hip. After she became familiar with practicing the multi-joint movement, the ball was placed further away to encourage the patient to coordinate the extensors and flexors of the knee and hip joints.

To facilitate bending or extending movements while standing and to hold the intermediate position of the knee joint, the patient performed exercises such as rising from a high chair, standing on one leg with assistance, lunging, and a stepping exercise similar to walking. During the exercises, a physical therapist paid attention to the knee joint and prevented it from hyperextending We did not use a ball as an EFT at this period.

\section{RESULTS}

At the time of discharge, 9 weeks after surgery, the right patellar dislocation no longer occurred. The ROM of the right knee was 0 to 155 degrees in a lying position. During walking, the ROM was improved ( 0 to 68 degrees) compared with the value 3 weeks after surgery, while compensatory movements such as hyperextension of the knee and side bending of the trunk were not observed (Fig. 3 and Fig. 4). The walking speed was $1.11 \mathrm{~m} / \mathrm{s}$, and the stride was $38.5 \mathrm{~cm}$. Because of the coordination between the knee and hip joint, the patient's gait was rhythmical and her walking speed was faster than before the intervention. She was able to walk more than 2 kilometers at a time, and to climb stairs with one step on each stair. A pair of insoles was made for her flat foot at the time of hospital discharge.

\section{DISCUSSION}

The patient's low cognitive function made it difficult for her to achieve some tasks, which negatively affected her motor learning. Therefore, a rehabilitation program that she could comprehend was needed. The EFT drew the patient's interest and facilitated her understanding. Furthermore, the EFT diverted her attention away from her body movement, which may have

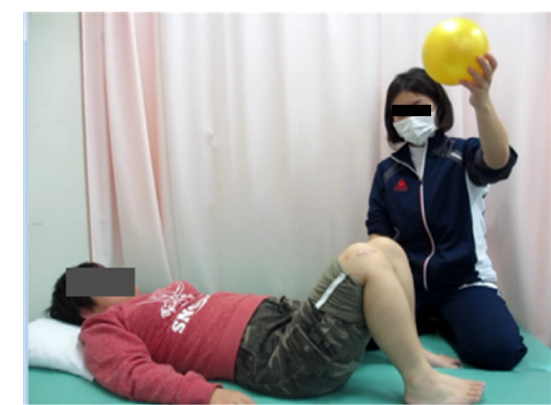

A. Start position

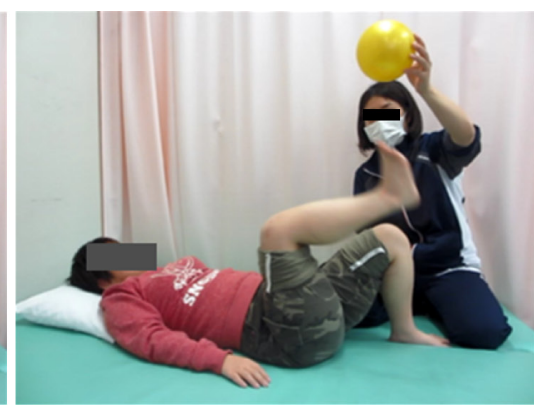

B. During movement

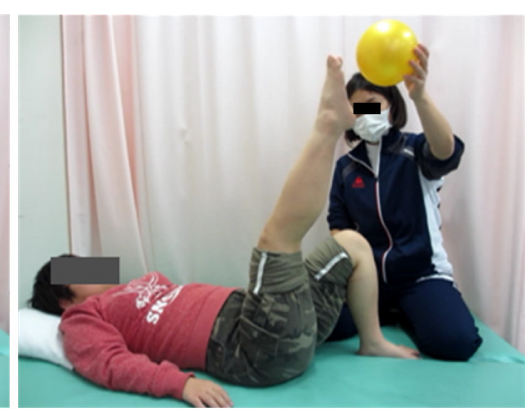

C. End position

Fig. 2. External focus training.

Reach and touch a ball with her toe and/or knee (A to B).

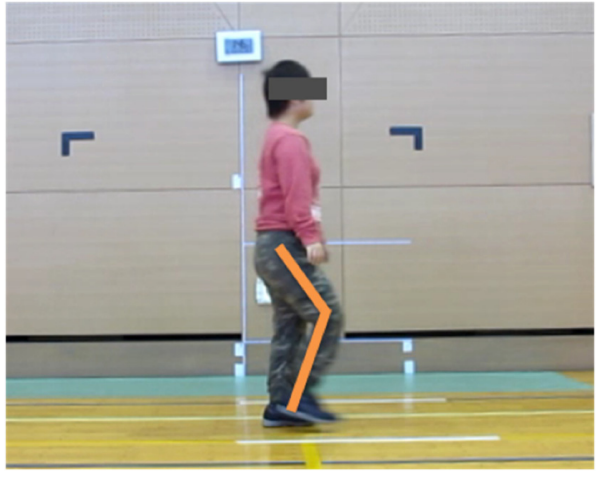

Fig. 3. Right knee joint while walking (Midswing phase). 9 weeks after surgery; knee joint bended for swing.

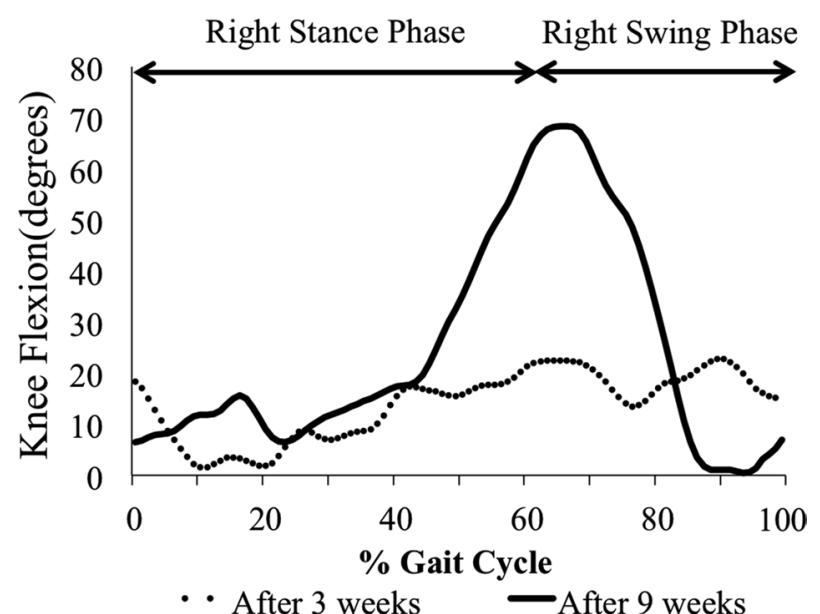

Fig. 4. Right knee angle in walking. 
helped to reduce her fear. The physical therapist was therefore able to facilitate the intended movements even though the patient had difficulties in comprehension.

In general, the prognosis of patients who undergo MPFL reconstruction is reported to be good ${ }^{13)}$. All patients return to preoperative levels of function and athletic participation ${ }^{13)}$. However, in this case, the patient experienced a problem with her post-operative walking ability. There were various reasons, including joint laxity, the knee extended in a fixed pattern to avoid pain, fixation of the lower extremity with a post-operative knee brace, and low cognitive function. Joint hypermobility derived from hypotonus and joint laxity affected not only the patellofemoral joint but also the tibiofemoral joint, and her knee joint had been unstable before surgery. In addition, preoperative claudication was considered to have made dynamic control of the knee joint difficult. Following EFT at an appropriate level of difficulty, the patient could demonstrate her maximum abilities without external support such as a brace. Even in this patient with DS and a low IQ, re-acquisition of motion was achieved through a stepwise joint motion exercise. First, we used an EFT because she couldn't selectively move her right knee. The EFT enabled her to specifically move her right knee. It was implemented under condition of an open kinetic chain using concept of external focus, thus we could move smoothly on to next closed kinetic chain exercises or weight loading, such as lunging or rising from a high chair afterward. We underwent an EFT approach to the patient with DS who was acknowledged as low IQ based on an objective scale examining intellectual level. The EFT approach was thought to be valid not only for patients with DS but for other pediatric patients. In this report, adopting the EFT concept to a patient with DS was novel, and incorporating this concept into a concrete term, EFT, was meaningful.

\section{Funding}

This work was supported by Grant-in-Aid for Community Research 2017 from Ibaraki Prefectural University of Health Sciences.

\section{Conflict of interest}

None.

\section{ACKNOWLEDGEMENT}

We thank the patient and her family for their warm cooperation, Yusuke Endo for analyzing the data on this patient, and Rachel Baron, PhD, from Edanz Group (www.edanzediting.com/ac) for editing a draft of this manuscript.

\section{REFERENCES}

1) Schieve LA, Boulet SL, Boyle C, et al.: Health of children 3 to 17 years of age with Down syndrome in the 1997-2005 national health interview survey. Pediatrics, 2009, 123: e253-e260. [Medline] [CrossRef]

2) Roizen NJ, Patterson D: Down's syndrome. Lancet, 2003, 361: 1281-1289. [Medline] [CrossRef]

3) Volman MJ, Visser JJ, Lensvelt-Mulders GJ: Functional status in 5 to 7-year-old children with Down syndrome in relation to motor ability and performance mental ability. Disabil Rehabil, 2007, 29: 25-31. [Medline] [CrossRef]

4) Semine AA, Ertel AN, Goldberg MJ, et al.: Cervical-spine instability in children with Down syndrome (trisomy 21). J Bone Joint Surg Am, 1978, 60: 649-652. [Medline] [CrossRef]

5) Bull MJ Committee on Genetics: Health supervision for children with Down syndrome. Pediatrics, 2011, 128: 393-406. [Medline] [CrossRef]

6) Merrick J, Ezra E, Josef B, et al.: Musculoskeletal problems in Down Syndrome European Paediatric Orthopaedic Society Survey: the Israeli sample. J Pediatr Orthop B, 2000, 9: 185-192. [Medline] [CrossRef]

7) Mik G, Gholve PA, Scher DM, et al.: Down syndrome: orthopedic issues. Curr Opin Pediatr, 2008, 20: 30-36. [Medline] [CrossRef]

8) Diamond LS, Lynne D, Sigman B: Orthopedic disorders in patients with Down's syndrome. Orthop Clin North Am, 1981, 12: 57-71. [Medline]

9) Dodd B: Differential diagnosis \& treatment of children with speech disorder, 2nd ed. London: Whurr, 2005.

10) Wulf G, Höß M, Prinz W: Instructions for motor learning: differential effects of internal versus external focus of attention. J Mot Behav, 1998, 30: 169-179. [Medline] [CrossRef]

11) Chiviacowsky S, Wulf G, Avila LT: An external focus of attention enhances motor learning in children with intellectual disabilities. J Intellect Disabil Res, 2013, 57: 627-634. [Medline] [CrossRef]

12) Uno Y, Mizukami H, Ando M, et al.: Reliability and validity of the new Tanaka B Intelligence Scale scores: a group intelligence test. PLoS One, 2014, 9 : e100262-e100262. [Medline] [CrossRef]

13) Han H, Xia Y, Yun X, et al.: Anatomical transverse patella double tunnel reconstruction of medial patellofemoral ligament with a hamstring tendon autograft for recurrent patellar dislocation. Arch Orthop Trauma Surg, 2011, 131: 343-351. [Medline] [CrossRef] 